\title{
Eating Behavior Changes of People with Obesity During the COVID-19 Pandemic
}

\author{
Vasfiye Bayram Deger (D) \\ Faculty of Health Sciences, Department \\ of Nursing (Public Health and Nutrition), \\ Mardin Artuklu Unıversıty, Mardin, \\ Turkey
}

Objective: The precautions taken during the pandemic period may cause stress-related eating behavior disorders. It was aimed to test this hypothesis, and the study was carried out to examine pandemic measures the effect of on the nutritional, depression and stress conditions of people with obesity.

Methods: The individuals who participated in the study were people with obesity who received follow-up dietary therapy in a private hospital. Three separate scales were applied to the individuals, which measured the desire to overeating request, depression status and stress-fighting status.

Results: This study was conducted on 368 individuals. Women had lower values of BMI $\left(28.57 \pm 3.89 \mathrm{~kg} / \mathrm{cm}^{2}\right)$ than men $\left(30.64 \pm 2.87 \mathrm{~kg} / \mathrm{cm}^{2}\right)$. When the scores of the excessive eating request scale mean scores before and during the pandemic were examined, it was seen that the scores of the individuals increased during the pandemic. In the multivariate regression model, it was seen that the increase of stress and BMI increased the FCQ score $(\mathrm{p}<0.001)$. Multiple regression models were created by taking into account the criteria that caused the score increase. Each variable can predict the FCQ score separately. The predictor significance order of variants on FCQ score $\beta$ values is as follows: the Patient Health Questionnaire-9 (PHQ-9) $(\beta=0.774)$, before pandemic FCQ $(\beta=0.601)$, the Perceived Stress Scale (PSS) $(\beta=-0.268)$, before pandemic $\mathrm{BMI}^{\mathrm{a}}(\beta=-0.223)$, during pandemic $\mathrm{BMI}^{\mathrm{b}}(\beta=0.073)$, and age $(\beta=-0.013)$.

Conclusion: COVID-19 pandemic, making applications such as quarantine in pandemic processes has successful results in being able to combat its. However, undesirable conditions such as stress can have serious negative consequences on other health measurements. It was observed in the results of this study that excessive eating food desire developed in people with obesity.

Keywords: people with obesity, COVID-19, pandemic, eating behaviour, stress, depression

\section{Introduction}

A new coronavirus, named the Coronavirus disease-2019 (COVID-19) by the World Health Organization (WHO), emerged in China in December 2019 and began to spread to many other countries at an unprecedented rate and became a worldwide pandemic. ${ }^{1}$ In 2019, containment efforts, such as "social distancing" policies and stay-at-home decisions to prevent the spread of COVID-19 pandemic, have led to a worsening of the situation in individuals with eating disorders and a further deterioration of the clinical condition of people with obesity diagnosed with eating disorders. Obesity, which was declared as an
Correspondence: Vasfiye Bayram Deger Faculty of Health Sciences, Department of Nursing (Public Health and Nutrition),

Mardin Artuklu Unıversıty, Campus, Diyarbakır Road 5th Km Artuklu, Mardin, 47000, Turkey

Tel +905321220606

Email vasfiyedeg@gmail.com 
epidemic by the WHO, has increased more with COVID-19, which was also declared as a pandemic by the WHO. Consequently, it has been observed that the pandemic triggered the obesity epidemic, which is an important public health problem. ${ }^{2}$

The first COVID-19 death in Turkey, which is among the developing countries, was identified on March 18, 2020. The number of deaths quickly increased to its peak level on April 19, with 124 people dying in a single day. The pandemic spreading so rapidly has made quarantine measures mandatory. For Turkey, which is also in a difficult period economically, fear and panic caused by both the pandemic and economic conditions have been at higher levels compared to other developed countries. However, both the low level of education and the economic problems of the people made it difficult to apply the quarantine rules. Especially in cities where the number of cases was very high, strict quarantine rules were applied, while in cities with a low number of cases, the situation was the opposite. The tightening of the quarantine rules has brought psychological difficulties, especially in some groups. In particular, the treatments that people with obesity should receive have been disrupted, and this has led to changes in eating behaviors of these individuals. It has been observed that people with obesity, which are a sensitive group, were most affected by this situation. Considering that $1 / 3$ of the adult population is people with obesity in Turkey, it is clear that the situation is actually much more serious for developing countries such as Turkey. The increase in obesity causes many chronic diseases. It causes progressive diseases with a burden of morbidity, especially diabetes and cardiovascular diseases, with a high mortality rate. $^{3}$ It has also been observed that the increase in these diseases will negatively affect the fight against the pandemic. ${ }^{4,5}$

Eating disorders are serious psychological disorders related to impaired eating behaviors and cognition and mostly affected all age groups. ${ }^{6}$ The desire to consume excessive food, one of the eating disorders, is more common in people with obesity due to stress. There has been a desire to consume more food in people with obesity, especially due to stress and anxiety, as in all individuals during the quarantine period, which has led to a further increase in obesity and disruption of treatment in these individuals. ${ }^{7,8}$ The fact that individuals are less physically active to reduce contact with other people during the pandemic period is also seen as one of the reasons for the increase in obesity. ${ }^{9}$ It has been observed that individuals' constant presence in the home environment causes them to need to eat more food and consume more starchy foods. ${ }^{10}$ While regulating government policies during the quarantine period, the importance of organizing programs in which people with obesity can be more physically active in the home environment and providing access to online consultancy services has been emphasized; otherwise, it has been observed that the increase in obesity is inevitable. ${ }^{11}$ On the other hand, stress, mood disorders, binge eating, weight variability, the severity of hypocaloric or hypercaloric diet should be more attentively considered when studying in inflammatory processes as COVID-19. ${ }^{12}$

In this study, it was aimed to examine the eating behavior changes of people with obesity during the COVID-19 pandemic period.

\section{Materials and Methods}

\section{Participants}

This study was carried out with individuals who applied to the nutrition and diet outpatient clinic of a private hospital and received special nutrition counseling. It consists of individuals who have been diagnosed with obesity in the last year and do not have any cancer, chronic disease, critically diseased, or pregnant and regular use drugs were excluded from the study. Individuals between the ages of 18 and 55 were included in the study.

\section{Study Design}

This study was conducted in an outpatient clinic Nutrition and Diet counseling in private hospital in the city of Mardin. Before the study started, permission was obtained from the hospital director. This hospital was chosen because pre-pandemic data can be accessed from the hospital records. As of February 2020, there were 614 people with obesity who regularly followed up in the clinic before the pandemic was declared. As of June 2020, it was observed that 385 individuals out of 614 individuals continued to come to the clinic for treatment after the declaration of pandemic. These individuals (368) were reached and agreed to participate in the study. This study was conducted in June and August. These individuals have been pre-interviewed 
via digital communication tools. And during the preinterviews, information was provided about the study. Demographic information and anthropometric measurements of the individuals were obtained using the data collection form during the pre-interviews. It was found that people with obesity, who participated in the study, filled the food cravings questionnaire (FCQ) within the routine procedures when they first applied to the clinic before the pandemic. These individuals were asked to fill the food cravings questionnaire, the patient health questionnaire, and the perceived stress scale during the pandemic period for the second time. The scale scores of the individuals were recorded and analyzed (Figure 1).

\section{Questionnaire}

Study data were collected by the researcher with the assistance of a managing nutritionist. While collecting the data, it was recorded digitally at the same time. The data collection form consists of three parts. The first part includes demographic information, education level and income level of the participants. In the second part, 4 short questions were asked about the negative consequences of the pandemic. In the third part, the Food Cravings Questionnaire (FCQ), the Patient Health Questionnaire-9 (PHQ-9) and Perceived Stress Scale (PSS) were filled in accordance with the aim of the study. The total time to collect information from an individual was between 15 minutes and 40 minutes.
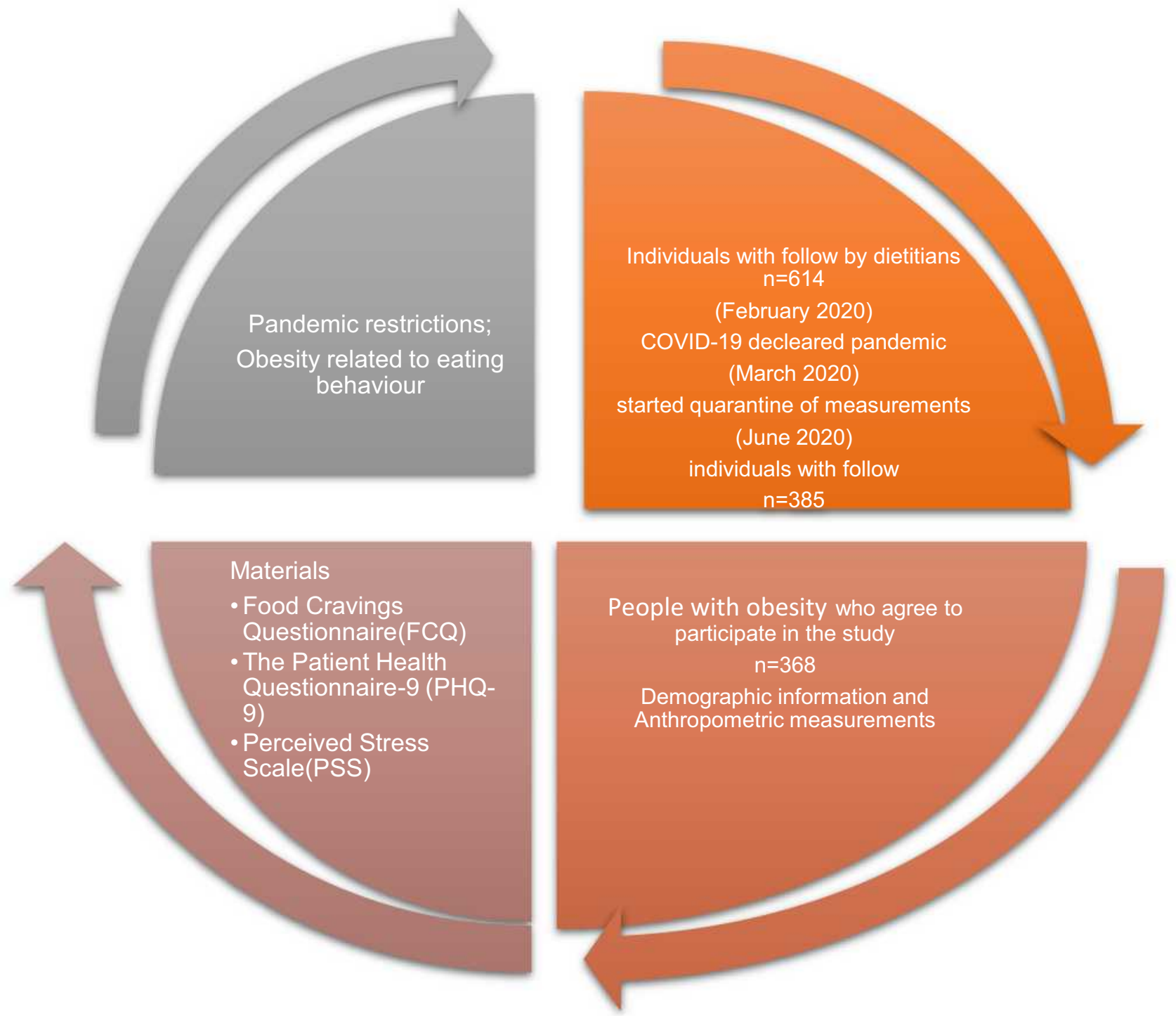

Figure I The design of the study. 


\section{Materials}

The Patient Health Questionnaire (PHQ-9)

The Patient Health Questionnaire-9 is a self-administered scale, which consists of nine items, used by healthcare professionals to assess and monitor the severity of depression. The questionnaire was developed to measure the mental state of the patient in the last two weeks. The total score ranges from 0 to 27 . The points received are evaluated as follows.

- 0-4 points; no depression

- 5-9 points; mild depression

- 10-14 points; moderate depression

- 15-27 points; severe depression. ${ }^{13}$

\section{Perceived Stress Scale (PSS)}

The perceived stress scale, which was developed by Cohen et al, has been used in many European countries and validity and reliability studies of the scale have been carried out. The PSS is a self-assessment scale developed to measure the level of stress experienced depending on the extent to which the individual assesses his or her life as unpredictable, uncontrollable and overloaded. The perceived stress scale was developed as a five-point Likerttype scale that consists of 14 items. The lowest and highest scores that a participant can obtain from this scale are 0 and 56, respectively. A high total score means a high level of perceived stress. Participants with a score range of 0-35 can be said to have a positive level of stress, cope effectively with stress, and the coping mechanisms they use are also functional. On the other hand, it can be suggested that the methods used by the participants with a score range of 36-56 to cope with stress are not functional and therefore they cannot deal with stress effectively. ${ }^{14}$ The adaptation study of the scale to Turkish society was conducted by Yerlikaya et al in 2006 and the scale was found to be valid and reliable. In this study, the Cronbach's alpha value was calculated as $0.86 .^{15}$

\section{Food Cravings Questionnaire (FCQ)}

Cepeda-Benito et al developed the Food Cravings Questionnaire (FCQ) in England in 2000 in order to measure excessive food craving objectives. ${ }^{15}$ The questionnaire used in this study is the Turkish version of the FCQ. Turkish validity and reliability study of the questionnaire was performed by Müftüoğlu et al. The scale consists of 9 sub-factors and 39 items. The Cronbach's Alpha Internal Consistency Coefficient for the integrity of the FCQ was determined as 0.97. All of the items in the scale are of 6-point Likert type. Accordingly, the increase of the individual's score on the questionnaire means that excessive food cravings have also increased. ${ }^{16}$

\section{Statistical Analysis}

All analyses were performed using the SPSS ${ }^{\circledR}$ that was used to evaluate and analyze the study data. A descriptive analysis was performed using numbers and percentages for categorical variables mean and standard deviation for continuous measurements. The Pearson correlation analysis was used for continuous variables to evaluate the correlation of variables with continuous scales, and the Student's $t$-test and ANOVA $F$-test were used for categorical variables with two or more levels.

In line with the aim of the study, the Pearson's Product Moment Correlation technique was used to examine the relationship between the variables. Before the regression analysis to be performed to determine the predictive power of the score of the FCQ, it was examined whether there was a multicollinearity problem among the variables by looking at the tolerance and variance inflation factor (VIF) values. According to the results, it was observed that the tolerance values were in the range of $0.430-0.869$, and the VIF values were in the range of $1.188-2.3244$, respectively. These values indicate that there is a multicollinearity between the independent variables. In this context, it was seen that the values obtained were within the desired range. Then, in the hierarchical regression analysis, continuous variables were added to the model, which can predict the score of the FCQ. Each added variable was kept constant and other variables were added to the model (pre-pandemic FCQ score, FCQ score during the pandemic period, PHQ, PSS, Body mass index (BMI), age, respectively). Finally, the model-6 with 6 variables was developed, which was found to be the model that could predict the score of the Food Cravings Questionnaire with the most variables.

\section{Results}

We received responses from 385 respondents, and 17 respondents did not complete the questionnaires. Eventually, we included 368 respondents who had completed the questionnaires (completion rate: $95.5 \%$ ). 
It was determined that $78.8 \%$ of the individuals who participated in the study were female and the remaining $21.2 \%$ were male, respectively. It was observed that the mean age of the female participants $(36.43 \pm 11.39$ years $)$ was higher than the mean age of the male participants (33.07 \pm 12.17 ). Furthermore, the majority of the individuals were single and divorced and $35.9 \%$ of them were found to be smoking. Majority of individuals are public officer (30.4\%) and not working (46.1\%). The majority of the individuals stated that their physical activity levels were decreased (65.2\%), and very few individuals stated that their physical activity levels were increased during the pandemic period (Table 1).

Table I Characteristics of the Individuals Who Participated in the Study

\begin{tabular}{|c|c|c|}
\hline & Frequency & \\
\hline Gender & $\mathrm{n}$ & (\%) \\
\hline Female & 290 & 78.8 \\
\hline Male & 78 & 21.2 \\
\hline Total & 368 & 100 \\
\hline $\mathrm{P}^{*}$ & 0.001 & $X^{2}=12.128$ \\
\hline \multicolumn{3}{|l|}{ Maritual status } \\
\hline Married & 157 & 42.7 \\
\hline Single & 177 & 48.1 \\
\hline Divorced & 34 & 9.2 \\
\hline \multicolumn{3}{|l|}{ Smoking status } \\
\hline Yes & 132 & 35.9 \\
\hline No & 236 & 64.1 \\
\hline \multicolumn{3}{|l|}{ Job or profession } \\
\hline Public officer & 112 & 30.4 \\
\hline Health employee & 21 & 5.7 \\
\hline Employee & 52 & 14.1 \\
\hline Not working & 170 & 46.1 \\
\hline Other Profession & 13 & 3.7 \\
\hline \multicolumn{3}{|c|}{$\begin{array}{l}\text { Physical activity levels during the } \\
\text { pandemic period }\end{array}$} \\
\hline Decreased & 240 & 65.2 \\
\hline Increased & 60 & 16.5 \\
\hline \multirow[t]{2}{*}{ Not changed } & 68 & 18.3 \\
\hline & Mean \pm SD & $\mathrm{p}^{* *}$ \\
\hline \multicolumn{3}{|l|}{ Age } \\
\hline Female & $36.43 \pm 11.39$ & 0.45 \\
\hline Male & $33.07 \pm 12.17$ & \\
\hline \multicolumn{3}{|l|}{ BMI $\left(\mathrm{kg} / \mathrm{cm}^{2}\right)$} \\
\hline Female & $28.57 \pm 3.89$ & 0.31 \\
\hline Male & $30.64 \pm 2.87$ & \\
\hline
\end{tabular}

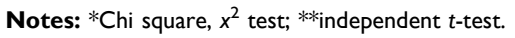

The rate of individuals who have to stay away from their families was $24.4 \%$. The lack of physical contact with friends of individuals was $78.2 \%$ during the periods when physical restrictions were applied. The rate of individuals leaving or being dismissed during the pandemic was $55.1 \%$ the rate of individuals, who had difficulty in accessing food during the pandemic, was found to be $79 \%$. During the pandemic period, the stress level of women was higher than men. It was also observed that the mean scores of the depression and FCQ were higher in women compared to men (Table 2).

While the average BMI value of the individuals before the pandemic was $34.61 \pm 4.64 \mathrm{~kg} / \mathrm{cm}^{2}$, it was measured as $30.09 \pm 3.74 \mathrm{~kg} / \mathrm{cm}^{2}$ during the pandemic period ( $\mathrm{p}<0.005$ ). Before the pandemic, the average FCQ score of the individuals at the time of application to the clinic was $134.18 \pm 42.94$, it increased to 143.40 \pm 47.80 points during the pandemic period $(\mathrm{p}<0.005)$ (Figure 2).

Considering the distribution of individuals according to the PHQ-9 and PSS scores, it was observed that the number of individuals with the highest value range of PHQ-9 score, 15-27, was the highest ( $\mathrm{n}=221,60.1 \%$ ). It was found that $38.9 \%(\mathrm{n}=143)$ of the individuals participated in the study had problems while coping with the stress (Figures 3 and 4).

The FCQ scores of the individuals participated in the study were evaluated according to PHQ-9 and PSS subgroups during the pandemic period. The mean FCQ score of individuals whose PHQ-9 score was between 15 and 27 points was measured as $148.61 \pm 47.05$ points, and this score was found to be the highest in this group. The mean FCQ score of the subgroups of the PSS scale was measured at a higher mean value $(144.31 \pm 42.21$ points) in the subgroup with a score of 0-35 (Table 3).

According to the multiple regression results made in Table 4, PSS score, BMI values can predict FCQ score, and this prediction is statistically significant $(p<0.005)$. The gender factor is a statistically significant factor in the prediction of the FCQ score $(\mathrm{p}<0.005)$.

The hierarchical regression analysis was performed to predict the $\mathrm{FCQ}^{\mathrm{a}}, \mathrm{PSS}^{\mathrm{b}}$ and PHQ-9 ${ }^{\mathrm{b}}$ scores, age and BMI $^{\mathrm{a}, \mathrm{b}}$ values of the participants. FCQ $^{\mathrm{a}}$, PSS $^{\mathrm{b}}$, PHQ- ${ }^{\mathrm{b}}$ scores, $\mathrm{BMI}^{\mathrm{a}}, \mathrm{BMI}^{\mathrm{b}}$ and age variables were added to the model respectively (Table 5). According to the results 
Table 2 Evaluation of the Quarantine Restrictions That Will Affect the Stress Levels of the Individuals During the Pandemic and the Scales Used in the Study

\begin{tabular}{|c|c|c|c|c|}
\hline & & n (\%) & $x^{2}$ & $\mathbf{p}^{*}$ \\
\hline Have to stay away from their families? & $\begin{array}{l}\text { Yes } \\
\text { No } \\
\text { Rarely }\end{array}$ & $\begin{array}{l}90(24.4) \\
202(54.8) \\
76(20.8)\end{array}$ & 2.933 & 0.001 \\
\hline Have to the lack of physical contact with friends? & $\begin{array}{l}\text { Yes } \\
\text { No } \\
\text { Rarely }\end{array}$ & $\begin{array}{l}288(78.2) \\
48(13.2) \\
32(8.6)\end{array}$ & 4.363 & 0.001 \\
\hline Have to leaving or being dismissed your jobs? & $\begin{array}{l}\text { Yes } \\
\text { No }\end{array}$ & $\begin{array}{l}165(44.8) \\
0\end{array}$ & 0.648 & 0.001 \\
\hline \multirow[t]{2}{*}{ Did you have difficulty in accessing food during pandemic period? } & $\begin{array}{l}\text { Yes } \\
\text { No } \\
\text { Rarely }\end{array}$ & $\begin{array}{l}291(79.1) \\
26(7.0) \\
51(13.8)\end{array}$ & 16.448 & 0.001 \\
\hline & Gender & Mean士SD & & $\mathbf{p}^{* *}$ \\
\hline PHQ-9 & $\begin{array}{l}\text { Male } \\
\text { Female }\end{array}$ & $\begin{array}{l}15.26 \pm 7.28 \\
16.10 \pm 7.44\end{array}$ & & 0.340 \\
\hline PSS & $\begin{array}{l}\text { Male } \\
\text { Female }\end{array}$ & $\begin{array}{l}30.73 \pm 13.63 \\
30.81 \pm 13.99\end{array}$ & & 0.543 \\
\hline FCQ (the pre-pandemic period) & $\begin{array}{l}\text { Male } \\
\text { Female }\end{array}$ & $\begin{array}{l}\mid 31.61 \pm 42.57 \\
134.00 \pm 42.93\end{array}$ & & 0.001 \\
\hline FCQ (during the pandemic period) & $\begin{array}{l}\text { Male } \\
\text { Female }\end{array}$ & $\begin{array}{l}134.30 \pm 48.20 \\
144.64 \pm 47.75\end{array}$ & & 0.001 \\
\hline
\end{tabular}

Notes: $*$ Chi square, $x^{2}$ test; $* *$ independent $t$-test.

obtained in the first model ( $\mathrm{F}=467.836)$, the FCQ score before the pandemic explains $82 \%$ of the variance of the score after the pandemic $\left(\mathrm{R}^{2}=0.827\right)$. The second model created by adding PSS $^{\mathrm{b}}$ to the model explains $83 \%$ of the variance of FCQ score after the pandemic and the change in determination coefficient $\left(\mathrm{R}^{2}\right)$ is significant ( $\mathrm{F}=4.825, \mathrm{p}<0.001)$. The third model created by adding PHQ- $9^{\mathrm{b}}$ to the model explains $87 \%$ of the variance of

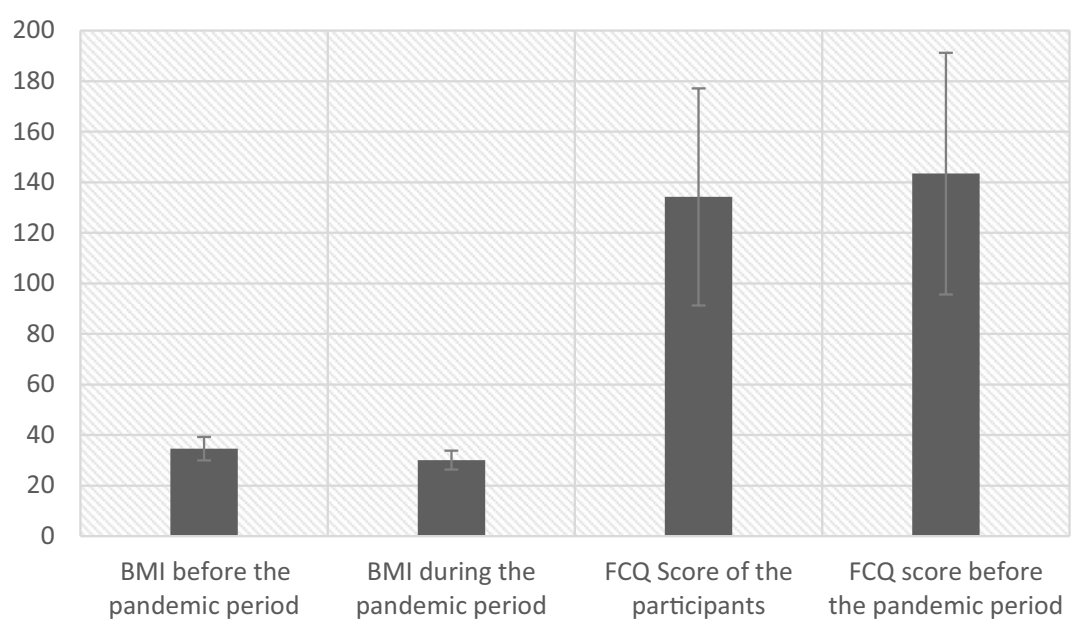

Figure 2 The mean BMI values and FCQ scores of the participants before and during the pandemic period and standard deviation values. Abbreviations: p, paired simple $t$ test; SD, standard deviation. 


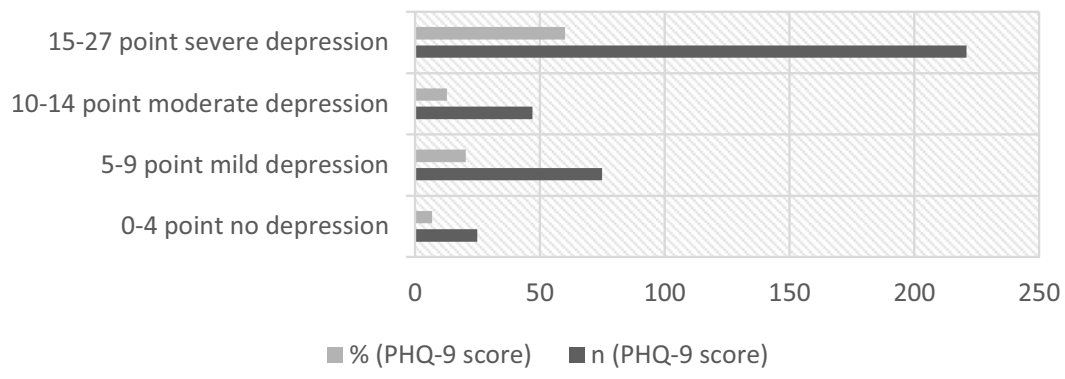

Figure 3 The distribution of individuals in subgroups of PHQ-9 scales, which show depression conditions during the pandemic period. Abbreviation: p, Chi square test.

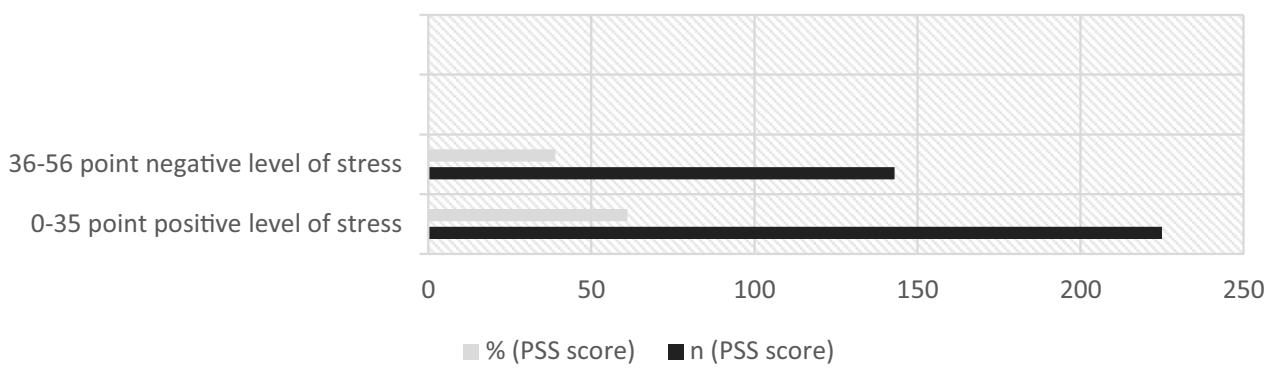

Figure 4 The distribution of individuals in subgroups of PSS scales, which show stress conditions during the pandemic period. Abbreviation: p, Chi square test.

the FCQ score after the pandemic, and the change in the coefficient of determination is significant $(\mathrm{F}=53.084$, $\mathrm{p}<0.001)$. The fourth model created by adding the pre-

Table 3 Mean and Standard Deviation Values of $\mathrm{FCQ}^{\mathrm{b}}$ Scores According to the PHQ-9 and PSS During the Pandemic Period

\begin{tabular}{|l|l|l|l|}
\hline & FCQ $^{\text {b Score }}$ & F & F*** $^{* *}$ \\
\hline PHQ-9 score & Mean \pm SD & 1.404 & 0.241 \\
\hline 0-4 point no depression & $141.12 \pm 42.98$ & & \\
5-9 point mild depression & $139.13 \pm 48.50$ & & \\
10-14 point moderate depression & $130.00 \pm 53.84$ & & \\
15-27 point severe depression & $148.61 \pm 47.05$ & & \\
\hline PSS score & & & $P^{* *}$ \\
\hline $\begin{array}{l}\text { 0-35 point positive level of stress } \\
\text { 36-56 point negative level of stress }\end{array}$ & $144.31 \pm 42.21$ & & 0.763 \\
\hline
\end{tabular}

Notes: ***ANOVA; **independent $t$-test; $\mathrm{FCQ}^{\mathrm{b}}$, during the pandemic FCQ score pandemic BMI value to the model explains $87 \%$ of the variance of the FCQ score, while the fifth model created by adding the BMI value after the pandemic to the model explains $97 \%$ of the variance of the FCQ score, respectively. The change in the coefficient of determination when both values were added to the model is significant $(\mathrm{F}=4.575 ; \mathrm{F}=0.406, \mathrm{p}<0.001)$. The sixth model, which was created by adding the age independent variable to the model, explains $97 \%$ of the variance of the FCQ score and the change in the coefficient of determination is significant $(\mathrm{F}=0.215, \mathrm{p}<0.001)$. Each variable can predict the FCQ score separately. The predictor significance order of variables on FCQ score $\beta$ values is as follows: PHQ- $9^{\mathrm{b}} \quad(\beta=0.774), \quad \mathrm{FCQ}^{\mathrm{a}}$ $(\beta=0.601), \operatorname{PSS}^{\mathrm{b}}(\beta=-0.268), \mathrm{BMI}^{\mathrm{a}}(\beta=-0.223), \mathrm{BMI}^{\mathrm{b}}$ $(\beta=0.073)$ and age $(\beta=-0.013)$.

Table 4 The Multivariate Regression Model of the Effect of PSS, PHQ-9 Scores, BMI ${ }^{\mathrm{b}}$ Values and Gender of the Individuals on Their FCQ $^{\mathrm{b}}$ Scores During the Pandemic Period

\begin{tabular}{|l|l|l|l|l|l|l|l|}
\hline Model & \multicolumn{2}{|l|}{ Unstandardized Coefficients } & Standardized Coefficients & $\boldsymbol{t}$ & $\boldsymbol{P}$ & $\boldsymbol{R}$ & $\boldsymbol{R}^{2}$ \\
\cline { 1 - 4 } Predictors & B & SE & Beta & & & \\
\hline Constant & 44.905 & 79.166 & & 0.567 & 0.573 & 0.389 \\
PHQ-9 & 0.269 & 1.744 & 0.034 & 0.154 & 0.001 & \\
PSS & -.524 & 1.124 & -.099 & -.467 & 0.643 & \\
BMI & 43.953 & 18.827 & 0.356 & 2.335 & 0.004 & \\
Gender & 0.832 & 2.121 & 0.057 & 0.392 & 0.697 & \\
\hline
\end{tabular}

Notes: During the pandemic period body mass index (BMI $\left.{ }^{\mathrm{b}}\right)$, the Patient Health Questionnaire (PHQ-9), Perceived Stress Scale (PSS). 
Table 5 The Multiple Hierarchical Regression Model of the Effect of FCQ ${ }^{a}$, PSS ${ }^{b}$, PHQ-9 $9^{b}$ Scores and BMI ${ }^{a}$, Values and Age of the Individuals on Their FCQ ${ }^{\mathrm{b}}$ Scores During the Pandemic Period

\begin{tabular}{|c|c|c|c|c|c|c|c|c|c|c|c|c|}
\hline \multirow[t]{2}{*}{ Predictors } & \multicolumn{4}{|c|}{ Model I } & \multicolumn{4}{|c|}{ Model 2} & \multicolumn{4}{|c|}{ Model 3} \\
\hline & B & $S E$ & $\boldsymbol{\beta}$ & $t$ & B & $S E$ & $\beta$ & $t$ & B & $S E$ & $\beta$ & $t$ \\
\hline $\mathrm{FCQ}^{\mathrm{a}}$ & 1.036 & 0.048 & 0.963 & $21.630 * * *$ & 1.608 & 0.264 & 1.493 & $6.088 * * *$ & 0.605 & 0.218 & 0.562 & $2.777 * * *$ \\
\hline PSS $^{b}$ & & & & & -2.708 & 1.233 & -.539 & $-2.197 * * *$ & -2.886 & 0.788 & -.574 & $-3.660 * * *$ \\
\hline PHQ-9 ${ }^{\mathrm{b}}$ & & & & & & & & & 7.420 & 1.018 & 0.986 & $7.286 * * *$ \\
\hline \multicolumn{13}{|l|}{$\mathrm{BMI}^{\mathrm{a}}$} \\
\hline \multicolumn{13}{|l|}{$\mathrm{BMI}^{\mathrm{b}}$} \\
\hline \multicolumn{13}{|l|}{ Age } \\
\hline$R^{2}$ & \multicolumn{4}{|l|}{0.827} & \multicolumn{4}{|l|}{0.835} & \multicolumn{4}{|l|}{0.874} \\
\hline$R^{2}$ change $F$ & \multicolumn{4}{|c|}{$467.836 * * *$} & \multicolumn{4}{|c|}{$4.825 * * *$} & \multicolumn{4}{|c|}{$53.084 * * *$} \\
\hline$F$ & \multicolumn{4}{|c|}{$467.836 * * *$} & \multicolumn{4}{|c|}{$260.516 * * *$} & \multicolumn{4}{|c|}{$442.642 * * *$} \\
\hline
\end{tabular}

Notes: Pre-pandemic $\mathrm{FCQ}^{\mathrm{a}}$ score, during the pandemic $\mathrm{PSS}^{\mathrm{b}}$ score, during the pandemic $\mathrm{PHQ}-9^{\mathrm{b}}$ score, pre-pandemic $\mathrm{BMI}$, during the pandemic $\mathrm{BMI}{ }^{\mathrm{b}}$, during the pandemic $\mathrm{FCQ}^{\mathrm{b}}$ score. *** $\mathrm{p}<0.05$.

Abbreviation: SE, standard error.

\section{Discussion}

COVID-19 poses an unprecedented public health threat, which has led to an increase in uncertainty-related stress in many people especially people with obesity. ${ }^{17}$ It has been observed that especially people with obesity try to cope with more stress during these periods. In quarantine periods, the difficulty in accessing food and the measures taken to reduce physical contact are also seen as the causes of stress in individuals. On the other hand, the difficulties in the treatment of people with obesity diagnosed with COVID-19 and the high mortality rate also contribute to the increased stress of people with obesity. ${ }^{2,3,5}$

People with obesity are limited during these periods to apply to health institutions for the treatment of obesity and to receive support for treatment. It has been observed that distancing individuals from treatment leads to a decrease in motivation and weight gain. The study results show that most people tend to change their eating behaviors when they feel stressed, with about $80 \%$ changing their calorie intake by increasing or decreasing their consumption behaviors. ${ }^{18}$ In this study, it was observed that while the number of patients followed before the pandemic was 600 , it decreased significantly after the declaration of the pandemic. This shows that the treatment of individuals is disrupted and the fight against obesity has been severely interrupted. In a study carried out to examine the causes of disruption in treatment, it was observed that most of the health institutions were used for the treatment of COVID19 and the individuals working in the obesity unit were also shifted to this area. ${ }^{19}$ Restrictions made to prevent physical contact such as quarantine during the pandemic period caused individuals to stay at the home more than other times. For these reasons, people with obesity have been reported to have increased anxiety levels during the pandemic period. ${ }^{20}$ It has been observed that this led to more food consumption and made it difficult to adapt to medical nutrition treatment. In a study that examined the nutritional diversity of individuals, the foods consumed by individuals before and after quarantine were examined. It was observed that consumption of foods such as sugary drinks and potato chips was increased during the quarantine period. ${ }^{21}$ In another study, in which the eating behaviors of individuals were examined, the data obtained from individuals before the pandemic was compared with the data obtained from individuals during the pandemic, and it was found that the eating behaviors of the individuals changed during the pandemic period, especially the foods with high-energy content were stored and consumed. ${ }^{10}$ This is a study suggesting that especially people with obesity have an increased tendency to consume more food during extreme stressful and distressing times and this situation causes an increase in the desire to consume more food due to mood changes. ${ }^{22}$ In this study, it was observed that the scores of the individuals indicating their 


\begin{tabular}{|c|c|c|c|c|c|c|c|c|c|c|c|}
\hline \multicolumn{4}{|c|}{ Model 4} & \multicolumn{4}{|c|}{ Model 5} & \multicolumn{4}{|c|}{ Model 6} \\
\hline B & $S E$ & $\beta$ & $t$ & B & $S E$ & $\beta$ & $t$ & B & $S E$ & $\beta$ & $t$ \\
\hline 0.703 & 0.212 & 0.653 & $3.309 * * *$ & 0.639 & 0.236 & 0.594 & $2.704 * * *$ & 0.647 & 0.240 & 0.601 & $2.698 * * *$ \\
\hline-1.283 & 1.061 & -.255 & -1.209 & -1.328 & 1.073 & -.264 & -1.238 & -1.349 & 1.087 & -.268 & $-1.24 \mid$ \\
\hline 5.811 & 1.227 & 0.772 & $4.734 * * *$ & 5.858 & 1.241 & 0.779 & $4.722 * * *$ & 5.824 & 1.258 & 0.774 & $4.63 I^{* * *}$ \\
\hline \multirow[t]{3}{*}{-2.605} & 1.218 & -.215 & $-2.139 * * *$ & -2.622 & 1.229 & -.216 & $-2.134 * * *$ & -2.708 & 1.257 & -.223 & $-2.154 * * *$ \\
\hline & & & & 0.902 & 1.415 & 0.065 & 0.637 & 1.006 & 1.450 & 0.073 & 0.694 \\
\hline & & & & & & & & -.053 & 0.115 & -.013 & -.464 \\
\hline \multicolumn{4}{|l|}{0.877} & \multicolumn{4}{|l|}{0.978} & \multicolumn{4}{|l|}{0.978} \\
\hline \multicolumn{4}{|c|}{$4.575 * * *$} & \multicolumn{4}{|c|}{$0.406 * * *$} & \multicolumn{4}{|c|}{$0.215^{* * *}$} \\
\hline \multicolumn{4}{|c|}{$367.035 * * *$} & \multicolumn{4}{|c|}{$288.582 * * *$} & \multicolumn{4}{|c|}{$234.800 * * *$} \\
\hline
\end{tabular}

food craving before the pandemic were lower, and their scores increased during the pandemic period. It was also seen that the mean BMI values of the individuals before the pandemic were higher and the BMI values determined during the pandemic were lower. This shows that the decrease in body weight of individuals continues during the pandemic.

During the pandemic period, the individuals showed signs of depression and the depression assessment scores of the majority of the individuals participated in the study were found to be high. These results have been found in many studies in the literature. ${ }^{23}$ In particular, quarantine processes, inability to be in social environments to reduce physical contact, and food transportation problems can trigger stress-related depression in people. ${ }^{24}$ In a study conducted with 1210 participants from 194 cities in China, it has been reported that the psychological state of $53.8 \%$ of the individuals participated in the study were affected moderately or severely due to the pandemic, while $16.5 \%$ of the participants showed moderate to severe depressive symptoms, $28.8 \%$ showed moderate to severe anxiety symptoms and $8.1 \%$ of them showed moderate to severe stress levels. ${ }^{25}$ Studies have shown that diseases with high contagious effects cause more stress in people and individuals cannot cope with stress during these periods. It has been found that people with obesity tend to eat more fatty and starchy foods in order to cope with the stress. ${ }^{26}$ It is not possible to say that their methods of coping with the stress were very successful. This is the result of many negativities that individuals have experienced during the pandemic period.

Quarantine measures taken to prevent the spread of infectious diseases have been found to lead to many eating behavior disorders in addition to symptoms of depression. ${ }^{27}$ It was observed that the increase in depression scale scores of individuals during the pandemic also caused an increase in the FCQ scores, which show the eating behavior disorder. Individuals have tended towards physical food to get rid of depression or to suppress the emotional hunger that depression causes in the body. The mean FCQ score of the individuals who cannot cope with the stress and the mean FCQ score of the individuals who can cope with the stress were found to be close to each other. It has been determined that physical activity levels of the individuals tend to decrease and become endangered with the maintenance of a healthy diet during the pandemic period. For example, by limiting daily grocery shopping, the consumption of fresh foods, especially fruits, vegetables and fish, is being replaced by highly processed foods such as junk food, snacks and ready-to-eat cereals. It is clear that these foods contain high amounts of fat, salt and sugar. The psychological and emotional responses of individuals to the COVID-19 pandemic cause individuals to consume more food and repeat this behavior. Eating behavior caused by negative emotions is known as "emotional eating". ${ }^{28}$ It has 
been observed that individuals are in a constant eating behavior, with their hunger and fastness being discarded, in order to respond to the quarantine and the negativities caused by this period. Individuals can develop a physiological reward satisfaction method through food consumption. ${ }^{29}$ In addition, situations such as boredom that may result from staying home for a long time will increase the tendency to overeat, often as a way to escape monotony. ${ }^{30}$ In the model applied to predict the food craving scale scores of individuals, it was observed that the eating behavior scores of the individuals were mostly affected by depression, while they were least affected by the age of the individuals participated in the study. In a study by Caroleo et al, a positive relationship was found between depression and BMI. ${ }^{31}$ Accordingly, it has been found that individuals with eating behavior disorders are prone to depression, but age is not very effective, and this condition can be seen at any age.

\section{Limitations}

This study has some limitations. First of all, the data in the study were collected with the information gathering form. Since the data of the study were collected during the pandemic period, it could not be carried out multi-center. Some of the study data included pre-pandemic data, so some participants' data were incomplete.

\section{Conclusions}

Although quarantine applied during pandemic periods is necessary to prevent the spread of the disease, it creates different negative psychological effects such as fear of transmission, anxiety, anger and boredom. In this study, we found that many factors that cause people with obesity to change their eating behaviors were observed during this period. Being constantly in the home to reduce physical contact has caused people with obesity to be seriously affected psychologically. The constant presence of people with obesity in the home during the COVID-19 pandemic has led to more food consumption and this issue cause increased FCQ scores their, consequently to the disruption of obesity treatment. Finally, for these reasons, people with obesity at high risk need more support for the negative psychological and social consequences of quarantine.

\section{Highlights}

- Measures taken during the pandemic period such as Quarantine are associated with stress and depression leading to unhealthy diet and reduced physical activity.
- The stress level increases and eating behavior disorders develop due to COVID-19.

- It has been observed that obesity treatment is also interrupted in pandemic periods.

- During the pandemic period, it was observed that individuals were significantly restricted in their physical activity.

\section{Abbreviations}

COVID-19, coronavirus disease-2019; WHO, World Health Organization; FCQ, Food Cravings Questionnaire; PSS, Perceived Stress Scale; PHQ-9, the Patient Health Questionnaire-9; BMI, body mass index.

\section{Data and Material Availability Statement}

I confirm that the data used during the research will not be showed with anybody or broadcasted in anywhere. The data sets generated during and analysed the current study are available from the corresponding author's reasonable request.

\section{Ethical Consideration}

This study was carried out in accordance with the latest version of the Declaration of Helsinki. The ethics committee approval for the study was obtained from the Clinical Research Ethics Committee of the Mardin Artuklu University.

\section{Informed Consent}

Informed consent was obtained in writing from all participants prior to the study.

\section{Acknowledgment}

The author would like to acknowledge all participants who agreed to participate in this study.

\section{Author Contributions}

The author of this article conducted each phase of the study alone and has made great efforts. Author made conception and design, acquisition of data, or analysis and interpretation of data; took part in drafting the article or revising it critically for important intellectual content; agreed to submit to the current journal; gave final approval of the version to be published; and agrees to be accountable for all aspects of the work. 


\section{Funding}

This work has not been financially supported by any individual or institution.

\section{Disclosure}

The author informs that there are no conflicts of interest in this work.

\section{References}

1. Touyz S, Lacey H, Hay P. Eating disorders in the time of COVID-19. BioMed Central. 2020.

2. Chua MWJ, Zheng S. Obesity and COVID-19: the clash of two pandemics. Obes Res Clin Pract. 2020;14(4):380-382. doi:10.1016/ j.orcp.2020.06.003

3. Dietz W, Santos-Burgoa C. Obesity and its implications for COVID19 Mortality. Obesity. 2020;28(6):1005. doi:10.1002/oby.22818

4. Sattar N, McInnes IB, McMurray JJ. Obesity a risk factor for severe COVID-19 infection: multiple potential mechanisms. Circulation. 2020;142(1):4-6. doi:10.1161/CIRCULATIONAHA.120.047659

5. Gao F, Zheng KI, Wang X-B, et al. Obesity is a risk factor for greater COVID-19 severity. Diabetes Care. 2020;43(7):e72-e74. doi: $10.2337 / \mathrm{dc} 20-0682$

6. Brownell KD, Walsh BT. Eating Disorders and Obesity: A Comprehensive Handbook. Guilford Publications; 2017.

7. Cooper M, Reilly EE, Siegel JA, et al. Eating disorders during the COVID-19 pandemic and quarantine: an overview of risks and recommendations for treatment and early intervention. Eat Disord;2020. 1-23. doi: 10.1080/10640266.2020.1790271

8. Moynihan AB, Van Tilburg WA, Igou ER, Wisman A, Donnelly AE, Mulcaire JB. Eaten up by boredom: consuming food to escape awareness of the bored self. Front Psychol. 2015;6:369. doi:10.3389/fpsyg.2015.00369

9. Mattioli AV, Puviani MB, Nasi M, Farinetti A. COVID-19 pandemic: the effects of quarantine on cardiovascular risk. Eur J Clin Nutr. 2020;1-4.

10. Pellegrini M, Ponzo V, Rosato R, et al. Changes in weight and nutritional habits in adults with obesity during the "lockdown" period caused by the COVID-19 virus emergency. Nutrients. 2020;12(7):2016.

11. Mattioli AV, Ballerini puviani M. Lifestyle at time of COVID-19: how could quarantine affect cardiovascular risk. Am J Lifestyle Med. 2020;14(3):240-242. doi:10.1177/1559827620918808

12. Hunt BJ, editor. Hemostasis at extremes of body weight. In: Seminars in Thrombosis and Hemostasis. Thieme Medical Publishers; 2018.

13. Kroenke K, Spitzer RL, Williams JB. The PHQ-9: validity of a brief depression severity measure. J Gen Intern Med. 2001;16(9):606-613. doi:10.1046/j.1525-1497.2001.016009606.x

14. Cohen S, Kamarck T, Mermelstein R. Perceived stress scale. In: Measuring Stress: A Guide for Health and Social Scientists. Vol. 10. 1994:1-2.

15. Cepeda-Benito A, Gleaves DH, Williams TL, Erath SA. The development and validation of the state and trait food-cravings questionnaires. Behav Ther. 2000;31(1):151-173.
16. Yerlikaya E, Inanc B. Psychometric properties of the Turkish translation of the perceived stress scale. In: IX National Psychological Counseling and Guidance Congress Abstract Book. 2007.

17. Müftüoğlu S, Kiziltan G, Ok MA. Adaptation of "Food Craving Questionnaire" for major depression patients into Turkish culture: a validity and reliability Study. Turkiye Klinikleri J Health Sci. 2017;2(1):13-22. doi:10.5336/healthsci.2016-54418

18. Rodríguez MÁ, Crespo I, Olmedillas H. Exercising in times of COVID-19: what do experts recommend doing within four walls? Rev Esp Cardiol. 2020. English Ed.

19. Dicker D, Bettini S, Farpour-Lambert N, et al. Obesity and COVID-19: the two sides of the coin. Obes Facts. 2020;13 (4):430-438. doi:10.1159/000510005

20. Balanzá-Martínez V, Atienza-Carbonell B, Kapczinski F, De Boni RB. Lifestyle behaviours during the COVID-19-time to connect. Acta Psychiatr Scand. 2020;141(5):399-400. doi:10.1111/acps.13177

21. Pietrobelli A, Pecoraro L, Ferruzzi A, et al. Effects of COVID-19 lockdown on lifestyle behaviors in children with obesity living in Verona, Italy: a longitudinal study. Obesity. 2020;28(8):1382-1385. doi:10.1002/oby.22861

22. Macht M. Characteristics of eating in anger, fear, sadness and joy. Appetite. 1999;33(1):129-139. doi:10.1006/appe.1999.0236

23. Leung G, Lam T, Ho L, et al. The impact of community psychological responses on outbreak control for severe acute respiratory syndrome in Hong Kong. J Epidemiol Community Health. 2003;57 (11):857-863. doi:10.1136/jech.57.11.857

24. Heaven PC, Mulligan K, Merrilees R, Woods T, Fairooz Y. Neuroticism and conscientiousness as predictors of emotional, external, and restrained eating behaviors. Int J Eat Disord. 2001;30 (2):161-166. doi:10.1002/eat. 1068

25. Wang C, Pan R, Wan X, et al. Immediate psychological responses and associated factors during the initial stage of the 2019 coronavirus disease (COVID-19) epidemic among the general population in China. Int $J$ Environ Res Public Health. 2020;17(5):1729. doi:10.3390/ijerph17051729

26. Abbas AM, Fathy SK, Fawzy AT, Salem AS, Shawky MS. The mutual effects of COVID-19 and obesity. Obes Med. 2020;19:100250. doi:10.1016/j.obmed.2020.100250

27. Haddad C, Kheir MB, Zakhour M, et al. Association between eating behavior and quarantine/confinement stressors during the Coronavirus disease 2019 outbreak. Journal of Eating Disorders. 2020;8(1). doi:10.1186/s40337-020-00317-0.

28. Van Strien T. Causes of emotional eating and matched treatment of obesity. Curr Diab Rep. 2018;18(6):35. doi:10.1007/s11892-018-1000-x

29. Singh M. Mood, food, and obesity. Front Psychol. 2014;5(925):2014. doi:10.3389/fpsyg.2014.00925

30. Havermans RC, Vancleef L, Kalamatianos A, Nederkoorn C. Eating and inflicting pain out of boredom. Appetite. 2015;85:52-57. doi:10.1016/j.appet.2014.11.007

31. Caroleo M, Carbone EA, Greco M, et al. Brain-behavior-immune interaction: serum cytokines and growth factors in patients with eating disorders at extremes of the body mass index (BMI) spectrum. Nutrients. 2019;11(9):1995. doi:10.3390/nu11091995

Diabetes, Metabolic Syndrome and Obesity: Targets and Therapy

Dovepress

\section{Publish your work in this journal}

Diabetes, Metabolic Syndrome and Obesity: Targets and Therapy is an international, peer-reviewed open-access journal committed to the rapid publication of the latest laboratory and clinical findings in the fields of diabetes, metabolic syndrome and obesity research. Original research, review, case reports, hypothesis formation, expert opinion and commentaries are all considered for publication. The manuscript management system is completely online and includes a very quick and fair peer-review system, which is all easy to use. Visit $\mathrm{http}: / / \mathrm{www}$.dovepress.com/testimonials.php to read real quotes from published authors. 